ఠ

\title{
Potential efficacy of preparations derived from Phaseolus vulgaris in the control of appetite, energy intake, and carbohydrate metabolism
}

This article was published in the following Dove Press journal:

Diabetes, Metabolic Syndrome and Obesity:Targets and Therapy

4 September 2009

Number of times this article has been viewed

\author{
Mauro AM Carai' \\ Noemi Fantini' \\ Barbara Loi' \\ Giancarlo Colombo' \\ Antonella Riva ${ }^{2}$ \\ Paolo Morazzoni ${ }^{2}$ \\ 'C.N.R. Institute of Neuroscience, \\ Cagliari, Italy; ${ }^{2}$ Indena SpA, Milan, Italy
}

Correspondence: Mauro AM Carai C.N.R. Institute of Neuroscience, Viale Diaz I82, I-09I 26 Cagliari (CA), Italy $\mathrm{Tel}+39070302227$

Tel +39070302076

Email caraimam@tiscali.it

\begin{abstract}
Preclinical data on extracts of and preparations derived from beans of Phaseolus vulgaris are reviewed as potential remedies for use in controlling food consumption, body weight, lipid accumulation, and glycemia. A growing body of evidence suggests that acute and chronic administration of $P$. vulgaris derivatives reduces food intake (including highly palatable foods), body weight, lipid deposit, and glycemia in rats exposed to multiple experimental procedures. Two possible lectin-mediated mechanisms of action have been proposed: (a) inhibition of $\alpha$-amylase, resulting in a reduced carbohydrate metabolism and absorption; (b) phytohemoagglutinininduced modulation of the activity of cholecystokinin and glucagon-like peptides, resulting in a reduced appetite. Preliminary clinical data, as well as reports focusing on the use of several traditional medicines, apparently extend these findings to humans. Should these initial clinical data be confirmed by future surveys, $P$. vulgaris derivatives might constitute novel remedies for the treatment of obesity and metabolic syndrome. Future studies are also expected to identify active structures leading to the development of new pharmaceutical agents.
\end{abstract}

Keywords: Phaseolus vulgaris extracts and derivatives, food intake, body weight, lipid accumulation, glycemia, obesity, diabetes, metabolic syndrome

This paper reviews the accumulating lines of experimental evidence suggesting that extracts of beans from Phaseolus vulgaris (Fabaceae) may be capable of reducing food intake (including highly palatable foods and fluids), body weight, lipid deposit, and glycemia in different, validated animal models of overeating, obesity, diabetes, and metabolic syndrome. A brief mention of the most relevant surveys testing $P$. vulgaris preparations on food intake and glycemia in humans is also given.

The genus $P$. vulgaris includes all species of legume seeds normally known as common beans. Archeological investigations showed that common beans originated on the American Continent, specifically in southern United States, Mexico, Central America, and the northern part of South America. In particular, the species P. vulgaris was introduced into Europe in the sixteenth century and since then it has become a very important crop in many regions of the world. Legume seeds are among the richest food sources of proteins, amino acids, complex carbohydrates, dietary fibers, and oligosaccharides for human and animal nutrition. ${ }^{1}$

\section{P. vulgaris extracts and food intake in laboratory animals} Preclinical investigations have unanimously reported how the acute, repeated administration of extracts of $P$. vulgaris, as well as some of their isolated ingredients, 
reduced food intake, body weight, and lipid accumulation in lean and obese laboratory animals..$^{2-13}$

Specifically, a study was performed to investigate the effect of a . vulgaris extract mixed with a starch-enriched chow on food intake and body weight in young, lean Hooded Lister rats. ${ }^{6}$ Restricted amounts of food were made available to rats to ensure the entire supply of $P$. vulgaris extract was consumed by each rat. The results of this study indicated a significant reduction in body weight gain in rat groups consuming chow mixtures containing 20 and $40 \mathrm{mg} /$ die $P$. vulgaris extract. The extract used in this study had a high content of $\alpha$-amylase inhibitors, suggesting that the possible mechanism of action underlying the reducing effect produced by this $P$. vulgaris extract on body weight gain was constituted by inhibition of the pancreatic enzyme $\alpha$-amylase, hampering starch metabolism and reducing feed efficiency (ie, food was less efficaciously converted into energy and, in turn, into body mass). Notably, the reduction in body weight gain secondary to exposure to the $P$. vulgaris extract was associated to a decrease in body content of lipids. Similar data were generated by a previous study, in which rats were fed with chow containing $\alpha$-amylase inhibitors from $P$. vulgaris; rats displayed a decrease in body weight gain and lipid accumulation. ${ }^{4}$

Two studies evaluated the effect of prolonged (700 to 800 consecutive days) exposure to a starch-enriched diet containing a $P$. vulgaris preparation. ${ }^{6,7}$ One of these two studies was designed to ensure that rats exposed to the $90 \mathrm{~g} / \mathrm{kg}$ kidney bean-based diet and pair-fed control rats (a) weighed approximately $100 \mathrm{~g}$ at the start of the experiment and (b) entirely consumed a fixed daily supply of food (resulting, in the treated rat group, in the consumption of the full daily dose of $P$. vulgaris extract). ${ }^{7}$ As shown in Figure 1, feed efficiency (defined as the body weight gain over the amount of food intake) was largely lower, especially over the first 3-month period, in P. vulgaris extract-treated rats than in control rats. Additionally, a significant reduction in body content of lipids was observed throughout the study in the rat group exposed to the $P$. vulgaris extract-containing diet when compared to the rat group exposed to the $P$. vulgaris extract-free diet. ${ }^{7}$ In the second study, control rats (exposed to a $P$. vulgaris extract-free diet) had a mean body weight gain of approximately $660 \mathrm{~g}$; conversely, rats consuming the diet including the $P$. vulgaris extract displayed a mean body weight gain of approximately 470 g. ${ }^{6}$

An additional study investigated the effect of repeated (21 consecutive days) daily administration, by intragastric gavage, of a single dose $(50 \mathrm{mg} / \mathrm{kg})$ of an extract of $P$. vulgaris prepared to contain high amounts of $\alpha$-amylase inhibitors on daily food intake and body weight in Wistar rats given access to a starch-enriched diet. ${ }^{2}$ Administration of the P. vulgaris extract resulted in a $15 \%$ reduction, in comparison to vehicle-treated control rats, in food intake over the 21-day treatment period; this effect was associated with a reduction in body weight gain $(+52.0 \mathrm{~g}$ per rat and $-1.3 \mathrm{~g}$ per rat in the vehicle- and $P$. vulgaris extract-treated rat groups, respectively, at the end of the treatment period).

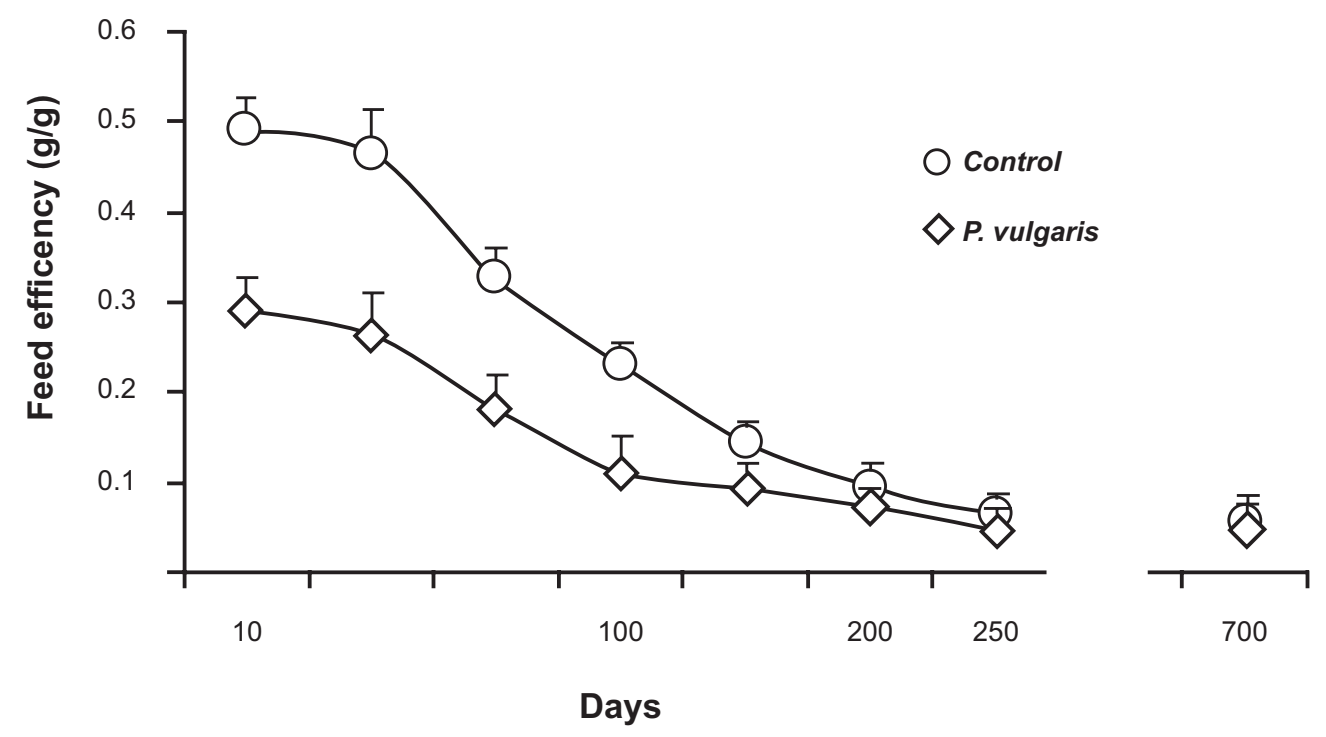

Figure I Reducing effect of the prolonged (700 consecutive days) ingestion of a Phaseolus vulgaris preparation, mixed in a starch-enriched diet, on feed efficiency [defined as the body weight gain (g) over the amount (g) of food intake] in Hooded Lister rats. Adapted from Grant G, Dorward PM, Buchan WC, Armour JC, Pusztai A. Consumption of diets containing raw soya beans (Glycine max), kidney beans (Phaseolus vulgaris), cowpeas (Vigna unguiculata) or lupin seeds (Lupinus angustifolius) by rats for up to 700 days: effects on body composition and organ weights. Br J Nutr. 1995;73:17-29.7 Copyright @ 1995 with permission of Cambridge University Press. 
Notably, these results were subsequently replicated in a study using rats with streptozotocin-induced diabetes. ${ }^{13}$ The repeated ( 22 consecutive days) daily administration of a single dose $(100 \mathrm{mg} / \mathrm{kg})$ of the P. vulgaris extract used in the previous study with Wistar rats (see also above) resulted in an approximately $25 \%$ reduction in daily food intake. ${ }^{12}$ This effect was paralleled by a reduction in body weight gain.

Beside the action of $\alpha$-amylase inhibitors, another mechanism for the reducing effect of $P$. vulgaris extracts on food intake and body weight has been proposed. As described in detail below, this mechanism involves phytohemoagglutinin, a lectin present at high levels in $P$. vulgaris. A series of experiments has been conducted to test this hypothesis. Specifically, an extract of $P$. vulgaris characterized by a high phytohemoagglutinin content was mixed to the diet; genetically obese Zucker rats were exposed to restricted daily amounts of food to ensure ingestion of the entire daily dose of phytohemoagglutinin by all rats. ${ }^{9}$ Repeated exposure to this diet resulted in reductions of $25 \%$ and $20 \%$, in comparison to control rats (given an identical daily amount of phytohemoagglutinin-free chow), in body weight gain and body fat content, respectively. In an additional experiment ${ }^{11}$ purified phytohemoagglutinin from $P$. vulgaris beans was acutely administered (by intragastric gavage), at a dose of $100 \mathrm{mg} / \mathrm{kg}$, to fasted Wistar rats given access to regular rat chow. Treatment with phytohemoagglutinin resulted in a marked reduction in food intake throughout the entire dark phase of the light/dark cycle (ie, the period of maximal activity in rats). The reducing effect of phytohemoagglutinin had a relatively slow onset, being manifest after approximately 5 hours; at the end of the dark phase, food intake was reduced by approximately $40 \%$ in phytohemoagglutinin-treated rats in comparison to vehicle-treated rats.

This laboratory has recently conducted a study aimed at assessing the effect of a $P$. vulgaris extract prepared in order to produce a potential dual action: inhibition of $\alpha$-amylase and a phytohemoagglutinin-induced anorectic effect. To this end BeanBlock ${ }^{\circledR}$ (prepared by Indena SpA, Milan, Italy), the extract tested, exerted an inhibitory activity on $\alpha$-amylase equal to $1400 \mathrm{U} / \mathrm{mg}$ and an hemoagglutinating activity equal to $16 \mathrm{HAU} / \mathrm{mg}$. The extract was added to a starch-enriched diet (Altromin RP $1000^{\circledR}$; Rieper, Vandoies, Italy); pellets containing $0 \%, 0.5 \%, 1 \%$, and $3 \%$ P. vulgaris extract were prepared. Singly housed, male adult Wistar rats (Charles River Laboratories, Calco, Italy) were divided into 4 groups of $n=6$ to 7 , matched for body weight, and fed with the above-mentioned food pellets with unlimited access for 24 hours/day over 10 consecutive days (treatment phase).
Rats from all groups were then given unlimited access to the plain diet (with $0 \%$ P. vulgaris extract) for an additional 14 consecutive days (post-treatment phase). Food and water intake, as well as rat body weight, were recorded once a day.

Exposure to the four different diets resulted in a concentration-dependent suppression in daily food intake over the first 3 days of treatment (Figure 2, top panel). On days 1 and 2, daily food intake in the rat group exposed to the diet containing $3 \%$ P. vulgaris extract was approximately $90 \%$ lower than that recorded in control rats (fed with the $0 \%$ P. vulgaris extract). However, on continuing treatment, tolerance to the anorectic effect of the $P$. vulgaris extract developed, as indicated by the virtually complete lack of any difference in daily food intake among the four rat groups from day 8 of treatment (Figure 2, top panel). This tolerance developed even though rats exposed to the most concentrated diets ingested daily amounts of $P$. vulgaris extract 2 to 3 times higher than those ingested during the first days of treatment. In the post-treatment phase, a relatively long period of overeating developed; this phenomenon was dependent on concentration of the $P$. vulgaris extract included in the previous rat diet and peaked up to $50 \%$, in comparison to control rats, on day +4 in the $3 \%$ P. vulgaris extract-treated rat group (Figure 2, top panel). Overeating tended to decrease progressively and vanished when rat body weight virtually achieved control values (see below).

Reduced daily water intake was observed only in the rat group consuming the $3 \% P$. vulgaris extract; however, this effect vanished on continuing treatment (Figure 2, center panel). Erratic differences in daily water intake were observed among the four rat groups during the 14-day posttreatment period (Figure 2, center panel).

In agreement with the reducing effect on food intake, rat body weight was greatly reduced in a concentrationdependent fashion by the ingestion of $P$. vulgaris extract (Figure 2, bottom panel). Specifically, in the rat group exposed to the diet containing 3\% . vulgaris extract, the reduction in body weight peaked up to $8 \%$ on day 3 , respect to values recorded immediately prior to start of the experiment. In the post-treatment phase, overeating (see above) led to a regaining of rat body weight (Figure 2, bottom panel); indeed, rate of rat body weight increase varied between control rats and animals previously exposed to the $P$. vulgaris extract.

\section{P. vulgaris extracts and intake of palatable food in laboratory animals}

Recent lines of evidence indicate that $P$. vulgaris extracts may also be effective in reducing intake of highly palatable foods. 

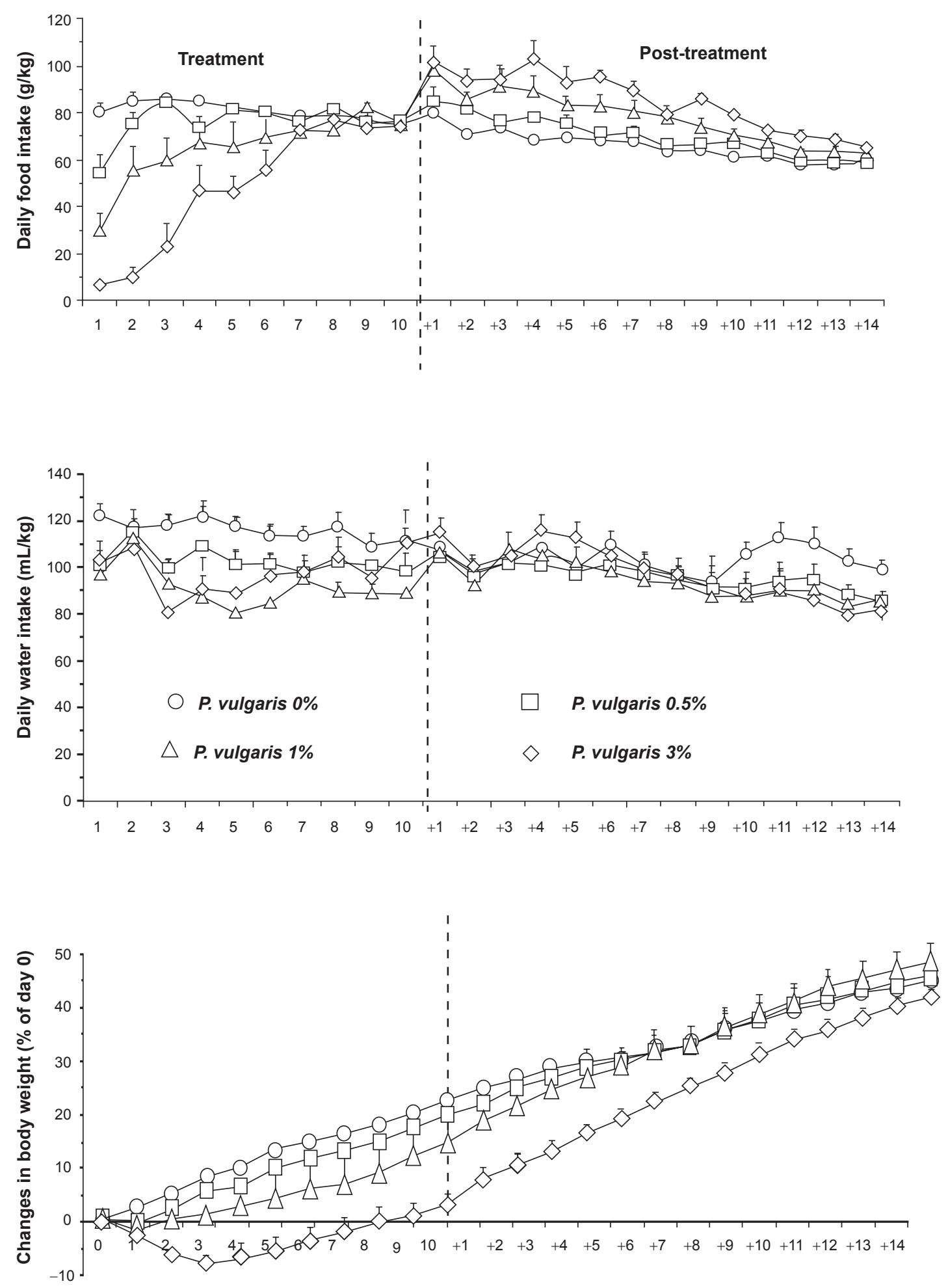

\section{Days}

Figure 2 Reducing effect of the repeated (10 consecutive days) ingestion of a Phaseolus vulgaris extract, mixed - at the concentrations of $0 \%$, $0.5 \%$, $1 \%$ and $3 \%$ - to a starchenriched diet, on daily food (top panel) and water (center panel) intake, as well as changes in body weight (expressed as percent of baseline) (bottom panel) in Wistar rats. Each point is the mean \pm SEM of $n=6$ to 7 rats. Hatched vertical lines indicate the end of the 10-day treatment phase and the start of the 14 -day post-treatment phase. ANOVA results - Food intake, treatment phase: $F_{\text {diet }}(3,21)=10.42, P<0.0005 ; F_{\text {time }}(9,189)=22.58, P<0.0001 ; F_{\text {interaction }}(27,189)=8.79, P<0.0001$; Food intake, posttreatment phase: $\mathrm{F}_{\text {diet }}(3,2 \mathrm{I})=12.93, P<0.000 \mathrm{I} ; \mathrm{F}_{\text {time }}(\mathrm{I} 3,273)=43.78, P<0.000 \mathrm{I} ; \mathrm{F}_{\text {interaction }}(39,273)=1.69, P<0.0 \mathrm{I} ;$ Water intake, treatment phase: $\mathrm{F}_{\text {diet }}(3,2 \mathrm{I})=3.47, P<0.05$; $\mathrm{F}_{\text {time }}(9,189)=2.38, P<0.05 ; \mathrm{F}_{\text {interaction }}(27,189)=0.97, P>0.05 ;$ Water intake, post-treatment phase: $\mathrm{F}_{\text {diet }}(3,2 \mathrm{I})=0.40, P>0.05 ; \mathrm{F}_{\text {time }}(\mathrm{I} 3,273)=\mathrm{I}$ (4.76, $P<0.000 \mathrm{I} ; \mathrm{F}_{\text {in }}$ $(39,273)=2.60, P<0.000 I$; Body weight changes, treatment phase: $F_{\text {diet }}(3,2 I)=7,44, P<0.005 ; F_{\text {time }}(9,189)=79.94, P<0.000 I ; F_{\text {interaction }}(27,189)=3.23, P<0.000 I ; B$ ody weight changes, post-treatment phase: $\mathrm{F}_{\text {diet }}(3,2 \mathrm{I})=2.3 \mathrm{I}, P>0.05 ; \mathrm{F}_{\text {time }}(13,273)=458.37, P<0.000 \mathrm{I} ; \mathrm{F}_{\text {interaction }}(39,273)=6.55, P<0.000 \mathrm{I}$. 
As an example, a recent study by this laboratory found that the acute administration of a P. vulgaris extract (BeanBlock ${ }^{\circledR}$ ) suppressed the intake of butter cookies in pre-satiated rats. Specifically, singly housed adult male Wistar rats (Charles River Laboratories) were habituated to feed [standard rat chow (Mucedola, Settimo Milanese, Italy)] for 3 hours per day (the first 3 hours of the dark phase); no food was available during the remaining 21 hours. Water was available 24 hours per day. This procedure led to fully satiated rats at the end of the 3-hour feeding period. On the test day, the 3-hour period of access to regular food was followed by 1-hour availability of the highly palatable butter cookies. Rats were divided into 4 groups of $n=7$, matched for body weight and food intake during the last 3 days preceding the experiment. The P. vulgaris extract was administered intragastrically at doses of $0,50,200$, and $500 \mathrm{mg} / \mathrm{kg}$ at the time of removal of the regular food (immediately prior to presentation of the butter cookies). Intake of butter cookies was recorded at the end of the 1-hour exposure period.

Even though rats were fully satiated, vehicle-treated rats consumed large amounts of butter cookies over the 1-hour exposure period. Acute administration of the P. vulgaris extract resulted in a dose-dependent suppression of this extraintake of food. Specifically, intake of butter cookies in rats treated with 50, 200, and $500 \mathrm{mg} / \mathrm{kg}$ P. vulgaris extract was approximately $75 \%, 85 \%$, and $90 \%$ lower, respectively, than that recorded in vehicle-treated rats (Figure 3).

Another experiment (this laboratory, unpublished results) found that the same $P$. vulgaris extract previously tested in the experiment with the butter cookies (see above) dosedependently suppressed the polydipsic-like consumption of a highly palatable, chocolate-flavored beverage in rats. Notably, the $P$. vulgaris extract was shown to be more potent and effective in reducing intake of the chocolate-flavored beverage than regular food pellets. In that particular study, the chocolate-flavored beverage provided a modest caloric supply ( $<1 / 15$ than that provided by regular food pellets), resulting in a beverage mostly consumed by rats because of its palatability rather than its caloric properties. This suggests that $P$. vulgaris extracts may exert their suppressing effects on palatable food with mechanisms other than those related to the nutritive properties of food.

\section{$P$. vulgaris extracts and glycemia in laboratory animals}

P. vulgaris extracts have also been found to reduce glycemia $^{12-14}$ and glucose absorption ${ }^{5}$ in laboratory animals. As an example, the study by Tormo et al in which rats were repeatedly treated with $50 \mathrm{mg} / \mathrm{kg}$ of $P$. vulgaris extract (with a high content of $\alpha$-amylase inhibitors) and fed with a starch-enriched diet, demonstrated that the reducing effect of $P$. vulgaris extract on food intake and body weight was associated with a steady reduction in glycemia, measured once every other day and 1 hour after lights-off (this time schedule was likely chosen to measure the glycemia derived from the last daily meal, that usually occurs in the last period of the dark phase of the light/dark cycle under which rats were housed). ${ }^{12}$ An additional experiment found that acute administration of the same $P$. vulgaris extract reduced glycemia in rats forcedly administered (by intragastric gavage) with a fixed amount $(2 \mathrm{~g} / \mathrm{kg})$ of potato starch. ${ }^{12}$

Similar results were collected in rats made diabetic by treatment with streptozotocin. ${ }^{13}$ Specifically, newborn rats were treated with streptozotocin to induce pancreatic injury, resulting in reduction of insulin content and hyperglycemia; in adulthood, rats were treated daily and for 22 consecutive days with $100 \mathrm{mg} / \mathrm{kg}$ P. vulgaris extract; glycemia was assessed every other day, 1 hour after lights-off. Treatment with $P$. vulgaris extract resulted in (a) a marked and progressively increasing reduction in glycemia in streptozotocintreated rats, reaching - at the end of the treatment - the values of vehicle-treated nonstreptozotocin-treated rats (Figure 4), and (b) a less marked - although significant - reduction in glycemia in non-streptozotocin-treated rats (Figure 4).

When $P$. vulgaris extracts with high contents of phytohemoagglutinin and low contents of $\alpha$-amylase inhibitors were tested, a lack of effect on glycemia was the most common outcome. As an example, repeated exposure to fixed amounts of phytohemoagglutinin-enriched diets resulted in slight, if any, reductions in glycemia in normal and obese rats. ${ }^{9-15}$

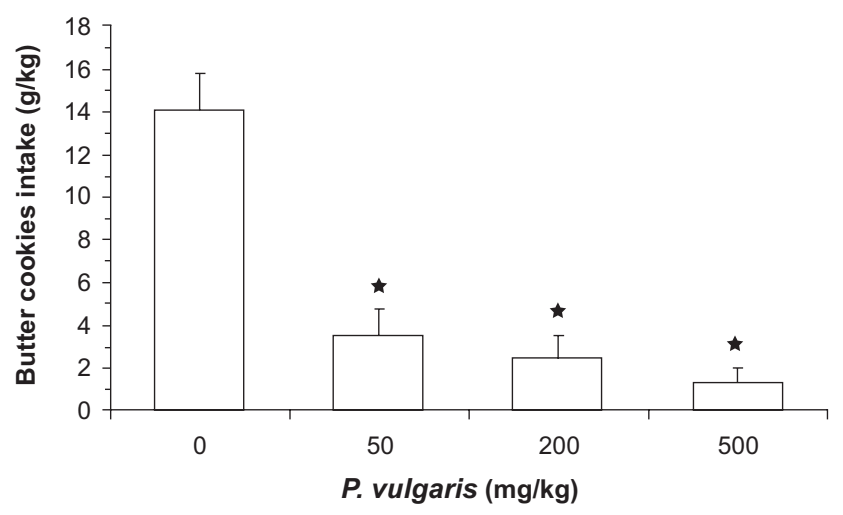

Figure 3 Reducing effect of the acute administration of a Phaseolus vulgaris extract on intake of butter cookies in pre-fed satiatedWistar rats having a I-hour access to butter cookies. Each bar is the mean \pm SEM of $n=7$ rats. ANOVA results: $F(3 ; 27)=245.55$, $P<0.000$ I; $* P<0.05$ with respect to vehicle-treated rats (Newman-Keuls test). 


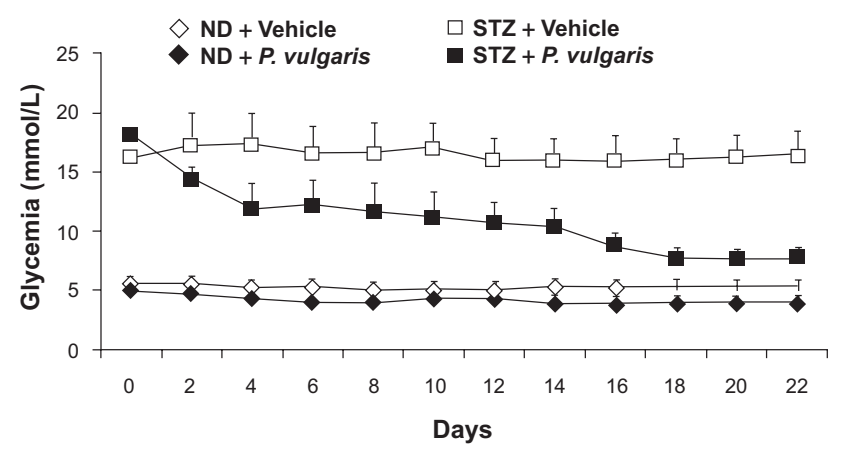

Figure 4 Reducing effect of the repeated (22 consecutive days) administration of a Phaseolus vulgaris extract on glycemia in control (ND) and streptozotocin-treated (STZ) rats. Glycemia was monitored every other day. Adapted from Tormo MA, Gil-Exojo I, Romero de Tejada A, Campillo JE. White bean amylase inhibitor administered orally reduces glycaemia in type 2 diabetic rats. Br J Nutr. 2006;96:539-544. Copyright (C) 2006 with permission of Cambridge University Press.

A recent experiment by this laboratory compared the effect of identical doses of a $P$. vulgaris extract (BeanBlock $\left.{ }^{\circledR}\right)$, prepared to contain both $\alpha$-amylase inhibitors and phytohemoagglutinin, and the standard anti-hyperglycemic drug, metformin, in rats. Specifically, singly housed adult male Wistar rats were fasted 24 hours before the start of the experiment. On the test day, rats were divided into 4 groups of $n=7$ to 8 , matched for body weight and glycemia, and treated intragastrically with vehicle, $500 \mathrm{mg} / \mathrm{kg}$ metformin (Sigma, Milan, Italy), and $500 \mathrm{mg} / \mathrm{kg}$ P. vulgaris extract. Thirty minutes later, rats were given $9 \mathrm{~g} / \mathrm{kg}$ food [starch-enriched chow (Altromin RP $1000^{\circledR}$; Rieper, Vandoies, Italy); an amount totally consumed - in less than 60 minutes - by fasted rats]. Glycemia was determined 0, 60, 120, and 360 minutes after food presentation. A small $(0.05 \mathrm{~mL})$ blood sample was collected from the tip of the tail of each rat and analyzed enzymatically [GL5 Analox ${ }^{\circledR}$ (Analox Ltd, London, UK)].

Metformin and P. vulgaris extract exerted a similar effect, inducing a reduction in glycemia of comparable magnitude at both 60- and 120-minute recording times (Figure 5, top panel). Accodingly, metformin and $P$. vulgaris extract reduced to a similar extent the area under the curve of the time-course of glycemia (Figure 5, bottom panel). These data indicate that P. vulgaris extracts may produce a reduction in post-prandial glycemia closely resembling that produced by metformin in rats exposed to a semi-naturalistic setting of a large meal after several hours fasting.

\section{Possible mechanisms of action}

Review of the existing literature suggests the involvement of two possible mechanisms of action in the reducing effect of $P$. vulgaris extracts on food intake, body weight, and glycemia. Both these mechanisms focus on the role of phytohemoagglutinin and $\alpha$-amylase inhibitors. The latter constituents belong to the class of lectins, highly represented in different cereals and pulses, including $P$. vulgaris. These lectins - together with arcelins, another type of lectins abundant in P. vulgaris - are homologous proteins displaying high degrees ( $40 \%$ to $95 \%$ ) of aminoacid sequence similarity. ${ }^{16-19}$

Pancreatic $\alpha$-amylase is an enzyme that catalyzes hydrolysis of $\alpha-(1,4)$-glycosidic bonds of starch polymers. ${ }^{20}$ Thus, inhibition of $\alpha$-amylase results in the suppression of starch metabolism and, in turn, a decrease in glycemia. ${ }^{12-20}$ It has also been reported that $\alpha$-amylase inhibitors delay gastric emptying, producing feelings of satiety, ${ }^{21-22}$ thus resulting in reduced food intake. ${ }^{12-13}$

Phytohemoagglutinin is known to bind to the stomach epithelial cells and to the brush border membrane of small intestine, cecum, and colon. ${ }^{5,11,23-25}$ This binding results in the stimulation of the release of cholecystokinin and glucagonlike peptides, ${ }^{11,23-26}$ two hormones playing a relevant role in digestive processes and also in the central control of appetite. In close agreement with the latter hypothesis, recent data from this laboratory indicate that treatment with the cholecystokinin receptor type ${ }_{\mathrm{A}}\left(\mathrm{CCK}_{\mathrm{A}}\right)$ antagonist, lorglumide, blocked the reducing effect of a $P$. vulgaris extract (BeanBlock ${ }^{\circledR}$ ) on food intake in rats (this laboratory, unpublished results), suggesting that phytohemoagglutinin-stimulated release of cholecystokinin and $\mathrm{CCK}_{\mathrm{A}}$ receptors are major players in the appetite-reducing effect of $P$. vulgaris extracts.

Another $\mathrm{CCK}_{\mathrm{A}}$ receptor-mediated action of phytohemoagglutinin is the stimulation of pancreatic secretion of $\alpha$-amylase in rats; ${ }^{27-29}$ this should result in an accelerated metabolism of ingested starch and, in turn, in a stimulation of food intake and increase in glycemia. However, this effect seems to be of limited relevance in the overall control of appetite and food intake, as it is likely overwelmed by the opposite, anorectic and hypoglycemic effects of phytohemoagglutinin itself and $\alpha$-amylase inhibitors.

\section{Human data and conclusions}

As reported above and recently discussed, ${ }^{10,30}$ accumulating lines of experimental evidence consistently indicate that extracts of $P$. vulgaris are effective in reducing appetite, body weight, lipid accumulation, hedonic properties of food, starch absorption and metabolism, and glycemia in different species of laboratory animals.

These data are consonant with reports on a traditional use, mainly in Central American and European Countries, of $P$. vulgaris preparations as "antidiabetic" remedies. 

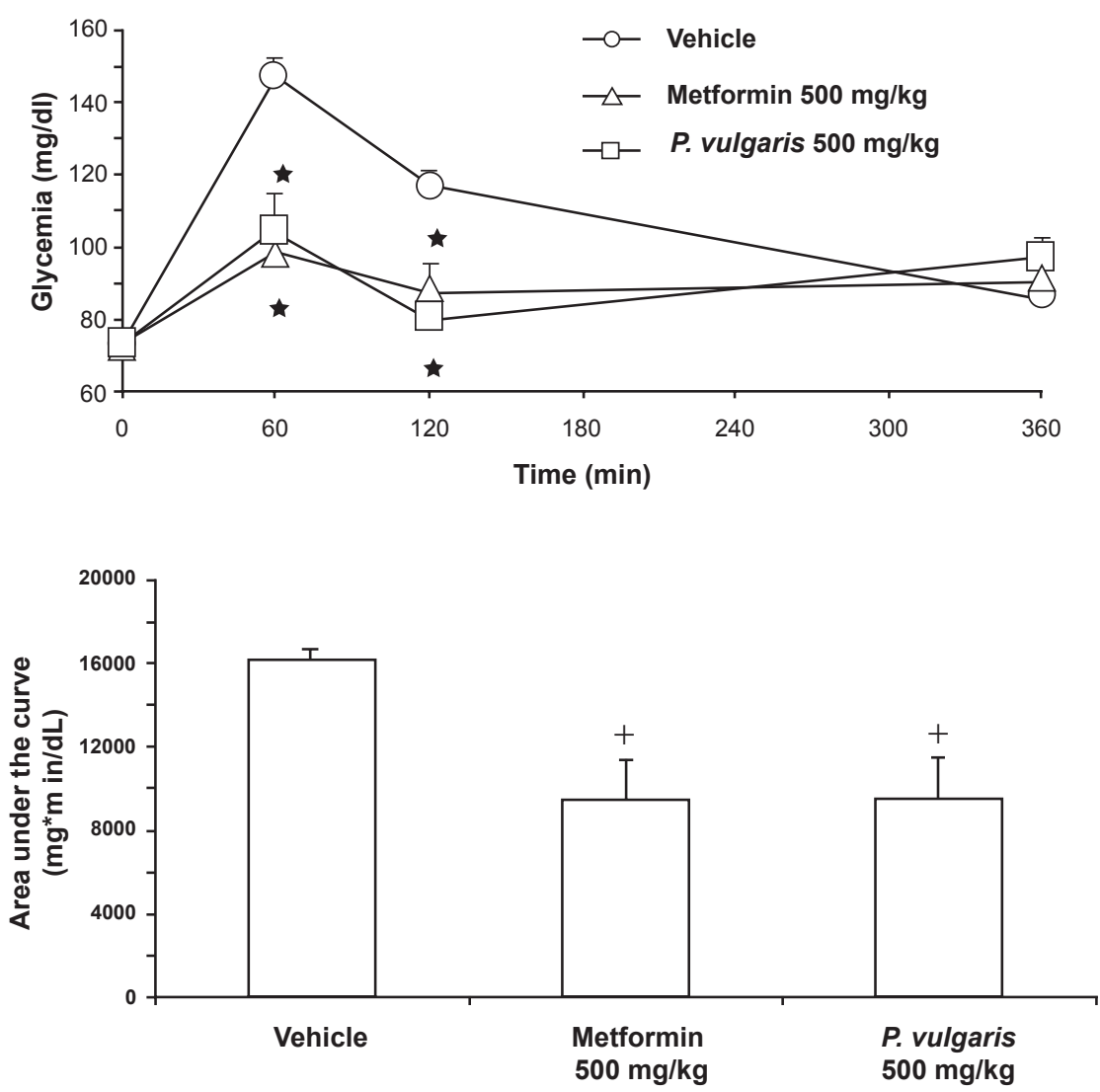

Figure 5 Similar reducing effect of a Phaseolus vulgaris extract and metformin on time-course of glycemia (top panel) and area under the curve of the time-course of glycemia (bottom panel) in Wistar rats given a I-hour (corresponding to the 0 - to 60 -minute time interval) access to a starch-enriched diet and water. Each point or bar is the mean \pm SEM of $n=7$ to 8 rats. ANOVA results - Time-course: $F_{\text {treatment }}(2,20)=9.13, P<0.005 ; F_{\text {time }}(2,40)=21.95, P<0.000 I ; F_{\text {interaction }}(4,40)=10.95, P<0.000 I ;$ Area under the curve: $F(2,20)=7.23, P<0.005$. $* P<0.005$ with respect to values of vehicle-treated rats at the same time interval (Newman-Keuls test); ${ }^{+} P<0.05$ with respect to values of vehicle-treated rats (Newman-Keuls test).

Accordingly, considerable benefit - especially during the developmental stages of the disease - has been reported in individuals taking $P$. vulgaris or preparations containing P. vulgaris as a main constituent. ${ }^{30,31-35}$

An interesting clinical trial, conducted in healthy subjects, found that intraluminal administration of a P. vulgaris-derived $\alpha$-amylase inhibitor suppressed (a) amylase activity in duodenum, jejunum, and ileum, (b) early postprandial glycemia rise, and (c) late post-prandial glycemia fall (secondary to a marked decrease in post-prandial insuline release). ${ }^{36-37}$ Confirmation of the hypoglycemic effect of a P. vulgaris-derived $\alpha$-amylase inhibitor is provided by a further study ${ }^{38}$ in which the $\alpha$-amylase inhibitor was administered to healthy subjects, resulting in a significant reduction in post-prandial glycemia. Further, Brugge and Rosenfeld ${ }^{39}$ investigated the effect of a $P$. vulgaris-derived $\alpha$-amylase inhibitor on hydrogen content in breath air after a starch-rich meal (spaghetti) in healthy subjects; breath hydrogen is inversely correlated with carbohydrate absorption. The P. vulgaris-derived $\alpha$-amylase inhibitor produced a 2-fold increase in hydrogen excretion rate compared to control subjects, suggesting a decreased carbohydrate absorption and/or metabolism. Similar results were collected by Boivin et al. ${ }^{38}$ In a recent additional series of studies, tendencies toward a reduction in body weight and waist circumference were observed in healthy subjects taking a preparation of $P$. vulgaris. ${ }^{40-42}$ Finally, a more recent randomized, double-blind, placebo-controlled trial found that a 2-month treatment with a dietary supplement made up of P. vulgaris and Cynara scolymus extracts increased the feeling of satiation (measured by the Haber's scale for hunger/satiety scoring) in healthy overweight and obese subjects. ${ }^{43}$

Together, these data suggest that extracts of $P$. vulgaris may constitute potentially interesting, novel remedies for the treatment of overweight and metabolic syndrome. Future studies, designed to confirm and extend those currently available in literature, are needed. Confirmation of the abovementioned, promising data would also allow a re-evaluation of $P$. vulgaris preparations, the reputation of which has 
frequently been hampered by the development of commercial preparations supported by large advertising campaign but devoid of any clinically demonstrated efficacy.

\section{Acknowledgments and disclosures}

The authors are grateful to S. Anne Farmer for language editing of the manuscript. The authors declare no conflicts of interest.

\section{References}

1. Geil PB, Anderson JW. Nutrition and health implications of dry beans: a review. J Am Coll Nutr. 1994;13:549-558.

2. Kakade ML, Evans RJ. Growth inhibition of rats fed raw navy beans (Phaseolus vulgaris). J Nutr. 1966;90:191-198.

3. Maranesi M, Carenini G, Gentili P. Nutritional studies on anti alphaamylase: I) Influence on the growt rate, blood picture and biochemistry and histological parameters in rat. Acta Vitaminol Enzymol. 1984;6: 259-269.

4. Maranesi M, Barzanti V, Biagi PL, Carenini G, Gentili P. Nutritional studies on anti alpha-amylase: II) Lipid metabolism investigation: fatty acid composition of organs and tissues. Acta Vitaminol Enzymol. 1984;6:347-353.

5. Donatucci DA, Liener IE, Gross CJ. Binding of navy bean (Phaseolus vulgaris) lectin to the intestinal cells of the rat and its effect on the absorption of glucose. J Nutr. 1987;117:2154-2160.

6. Grant G, Dorward PM, Pusztai A. Pancreatic enlargement is evident in rats fed diets containing raw soybeans (Glycine max) or cowpeas (Vigna unguiculata) for 800 days but not in those fed diets based on kidney beans (Phaseolus vulgaris) or lupinseed (Lupinus angustifolius). J Nutr. 1993:123:2207-2215.

7. Grant G, Dorward PM, Buchan WC, Armour JC, Pusztai A. Consumption of diets containing raw soya beans (Glycine max), kidney beans (Phaseolus vulgaris), cowpeas (Vigna unguiculata) or lupin seeds (Lupinus angustifolius) by rats for up to 700 days: effects on body composition and organ weights. Br J Nutr. 1995;73:17-29.

8. Pusztai A, Grant G, Duguid T, et al. Inhibition of starch digestion by $\alpha$-amylase inhibitor reduces the efficiency of utilization of dietary proteins and lipids and retards the growth of rats. J Nutr. 1995;125: 1554-1562.

9. Pusztai A, Grant G, Buchan WC, Bardocz S, de Carvalho AF, Ewen SW. Lipid accumulation in obese Zucker rats is reduced by inclusion of raw kidney bean (Phaseolus vulgaris) in the diet. Br J Nutr. 1998;79: 213-221.

10. Pusztai A, Bardocz S, Ewen SWB. Uses of plant lectins in bioscience and biomedicine. Frontiers in Bioscience. 2008;13:1130-1140.

11. Baintner K, Kiss P, Pfuller U, Bardocz S, Pusztai A. Effect of orally and intraperitoneally administered plant lectins on food consumption of rats. Acta Physiologica Hungarica. 2003;90:97-107.

12. Tormo MA, Gil-Exojo I, Romero de Tejada A, Campillo JE. Hypoglycaemic and anorexigenic activities of an $\alpha$-amylase inhibitor from white kidney beans (Phaseolus vulgaris) in Wistar rats. Br J Nutr. 2004;92:785-790.

13. Tormo MA, Gil-Exojo I, Romero de Tejada A, Campillo JE. White bean amylase inhibitor administered orally reduces glycaemia in type 2 diabetic rats. Br J Nutr. 2006;96:539-544.

14. Kotaru M, Iwami K, Yeh HY, Ibuki F. In vivo action of alpha-amylase inhibitor from cranberry bean (Phaseolus vulgaris) in rat small intestine. J Nutr Sci Vitaminol (Tokyo). 1989;35:579-588.

15. Bardocz S, Grant G, Pusztai A. The effect of phytoaemagglutinin at different dietary concentrations on the growth, body composition and plasma insulin of the rat. Br J Nutr. 1996;76:613-626.

16. Moreno J, Chrispeels MJ. A lectin gene encodes the $\alpha$-amylase inhibitor of the common bean. Proc Natl Acad Sci US A. 1989;86:7885-7889.
17. Ishimoto M, Suzuki K, Iwanaga M, Kikuchi F, Kitamura K. Variation of seed - amylase inhibitors in the common bean. Theor Appl Genet. 1995;90:425-429.

18. Sharma V, Surolia A. Analyses of carbohydrate recognition by legume lectins: size of the combining site loops and their primary specificity. J Molec Biol. 1997;267:433-445.

19. Lee SC, Gepts PL, Whitaker JR. Protein structures of common bean (Phaseolus vulgaris) $\alpha$-amylase inhibitors. J Agric Food Chem. 2002;50:6618-6627.

20. Santimone M, Koukiekolo R, Moreau Y, et al. Porcine pancreatic alphaamylase inhibition by the kidney bean (Phaseolus vulgaris) inhibitor $(\alpha-\mathrm{AI} 1)$ and structural changes in the $\alpha$-amylase inhibitor complex. Biochim Biophys Acta. 2004;1696:181-190.

21. Jain NK, Boivin M, Zinsmeister AR, Brown ML, Malagelada JR, Di Magno EP. Effect of ileal perfusion of carbohydrates and amylase inhibitor on gastrointestinal hormones and emptying. Gastroenterology. 1989;96:377-387.

22. Jain NK, Boivin M, Zinsmeister AR, Di Magno P. The ileum and carbohydrate-mediated feedback regulation of postprandial pancreatico-biliary secretion in normal humans. Pancreas. 1991;6: 495-505.

23. King TP, Pusztai A, Grant G, Slater D. Immunogold localization of ingested kidney bean (Phaseolus vulgaris) lectins in epithelial cells of the rat small intestine. Histochem J. 1986;18:413-420.

24. Bardocz S, Grant G, Ewen SW, et al; Reversible effect of phytohaemagglutinin on the growth and metabolism of rat gastrointestinal tract. Gut. 1995;37:353-360.

25. Herzig KH, Bardocz S, Grant G, Nustede R, Fölsch UR, Pusztai A. Red kidney bean lectin is a potent cholecystokinin releasing stimulus in the rat inducing pancreatic growth. Gut. 1997;41:333-338.

26. Rådberg K, Biernatt M, Linderoth A, Zabielski R, Pierzynowski SG, Weström BR. Enteral exposure to crude red kidney bean lectin induces maturation of the gut in suckling pigs. J Anim Sci. 2001;79:2669-2678.

27. Kordás K, Burghardt B, Kisfalvi K, Bardocz S, Pusztai A, Varga G. Diverse effects of phytohaemagglutinin on gastrointestinal secretions in rats. J Physiol (Paris). 2000;94:31-36.

28. Baintner K, Kiss P, Bardocz S, Pusztai A. Effect of orally administered plant lectins on intestinal liquor accumulation and amylase activity in rats. Acta Physiol Hung. 2004;90:97-107.

29. Baintner K, Kiss P, Pikli A, Peumans W, Bardocz S, Pusztai A. Origin and mediation of secretion induced by oral phytoemagglutinin (PHA) in rats. Acta Physiol Hung. 2004;91:221-233.

30. Obiro WC, Zhang T, Jiang B. The nutraceutical role of the Phaseolus vulgaris alpha-amylase inhibitor. Br J Nutr. 2008;100:1-12.

31. Román-Ramos R, Flores-Sáenz JL, Partida-Hernández G, Lara-Lemus A, Alarcón-Aguilar F. Experimental study of the hypoglycemic effect of some antidiabetic plants. Arch Invest Med (Mex). 1991;22:87-93.

32. Roman-Ramos R, Flores-Saenz JL, Alarcon-Aguilar FJ. Antihyperglycemic effect of some edible plants. J Ethnopharmacol. 1995; 11:25-32.

33. Petlevski R, Hadzija M, Slijepcevic M, Juretic D. Effect of 'antidiabetis' herbal preparation on serum glucose and fructosamine in NOD mice. J Ethnopharmacol. 2001;75:181-184.

34. Andrade-Cetto A, Heinrich M. Mexican plants with hypoglycaemic effect used in the treatment of diabetes. J Ethnopharmacol. 2005;99:325-348

35. Helmstädter A. Antidiabetic drugs used in Europe prior to the discovery of insulin. Pharmazie. 2007;62:717-720.

36. Layer P, Carlson GL, Di Magno EP. Partially purified white bean amylase inhibitor reduces starch digestion in vitro and inactivates intraduodenal amylase in humans. Gastroenterology. 1985;88:1895-1902.

37. Layer P, Zinsmeister AR, Di Magno EP. Effects of decreasing intraluminal amylase activity on starch digestion and postprandial gastrointestinal function in humans. Gastroenterology. 1986;91:41-48.

38. Boivin M, Zinsmeister AR, Go VL, Di Magno EP. Effect of a purified amylase inhibitor on carbohydrate metabolism after a mixed meal in healthy humans. Mayo Clin Proc. 1987;62:249-255. 
39. Brugge WR, Rosenfeld MS. Impairment of starch absorption by a potent amylase inhibitor. Am J Gastroenterol. 1987;82:718-722.

40. Udani J, Hardy M, Madsen DC. Blocking carbohydrate absorption and weight loss: a clinical trial using Phase 2 brand proprietary fractionated white bean extract. Altern Med Rev. 2004;9:63-69.

41. Udani J, Singh BB. Blocking carbohydrate absorption and weight loss: a clinical trial using a proprietary fractionated white bean extract. Altern Ther Health Med. 2007;13:32-37.
42. Celleno L, Tolaini MV, D'Amore A, Perricone NV, Preuss HG. A Dietary supplement containing standardized Phaseolus vulgaris extract influences body composition of overweight men and women. Int J Med Sci. 2007;4:45-52.

43. Rondanelli M, Orsini F, Opizzi A, Giacosa A, Bombardelli E, Villani S. The effect of 2-mo administration of a Phaseolus vulgaris and Cynara scolymus complex on feeling of satiation in healthy, overweight people. European Journal of Obesity. 2009;2(Suppl 2):234

\section{Publish your work in this journal}

Diabetes, Metabolic Syndrome and Obesity: Targets and Therapy is an international, peer-reviewed open-access journal committed to the rapid publication of the latest laboratory and clinical findings in the fields of diabetes, metabolic syndrome and obesity research. Original research, review, case reports, hypothesis formation, expert opinion and commentaries are all considered for publication. The manuscript management system is completely online and includes a very quick and fair peer-review system, which is all easy to use. Visit http://www.dovepress.com/testimonials.php to read real quotes from published authors.

Submit your manuscript here: http://www.dovepress.com/diabetes-metabolic-syndrome-and-obesity-targets-and-therapy-journal 